\title{
Simultaneous Determination of Cadmium and Lead Using PEDOT/PSS Modified Glassy Carbon Electrode
}

\author{
Sukeri Anandhakumar, Jayaraman Mathiyarasu*, \\ Kanala Lakshmi Narasimha Phani, Venkataraman Yegnaraman \\ Electrodics and Electrocatalysis Division, Central Electrochemical Research Institute, Karaikudi, India \\ E-mail:al_mathi@yahoo.com \\ Received December 30, 2010; revised March 4, 2011; accepted May 16, 2011
}

\begin{abstract}
In this work, we report the simultaneous determination of cadmium and lead using glassy carbon electrodes (GCE) modified by poly(3,4-ethylenedioxythiophene) (PEDOT) for linear sweep anodic stripping voltammetry (LSASV). The modification allows metal detection without involving oxygen removal, mechanical stirring and introduction of alloying additions such as $\mathrm{Hg}, \mathrm{Bi}, \mathrm{Sb}$, etc. during the pre-concentration step. Introduction of poly (4-styrenesulphonate) (PSS) as dopant in the PEDOT matrix improves reproducibility, stability and sensitivity in the detection. Both cadmium and lead peaks were readily quantifiable over the linear range of $2-10 \mu \mathrm{g} / \mathrm{ml}$ and the detection limit being $1.47 \mu \mathrm{g} / \mathrm{ml}$ and $1.15 \mu \mathrm{g} / \mathrm{ml}$ respectively. The calibration plot shows a linear response with correlation coefficient of 0.9911 and 0.9944 for cadmium and lead respectively. Thus, the GC/PEDOT/PSS modified electrode suggested as a suitable matrix for rapid monitoring of these heavy metals at trace levels.
\end{abstract}

Keywords: Stripping Voltammetry, Cadmium, Lead, Conducting Polymer, PEDOT-PSS, Heavy Metals

\section{Introduction}

Contamination of water by trace levels of heavy metals presents a major current environmental threat, resulting in an ever-increasing demand for the detection and monitoring of metal contaminants [1]. Electroanalytical techniques provide efficient, versatile and highly sensitive method of detecting a wide range of inorganic and organic substances at very low concentrations [2]. Anodic stripping voltammetry (ASV) is one of the most efficient techniques in this field, owing to an effective cathodic pre-concentration step, in which the analyte metal ion is reduced and deposited onto the electrode surface as a thin layer, followed by a stripping step, the results of which are readily quantifiable.

During the development of ASV over the past 50 years, mercury film electrodes (MFE) and hanging mercury drop electrode have been used due to their high sensitivity and remarkable reproducibility [3-5]. Due to its toxicity, the traditional mercury drop electrode is being progressively replaced by modified glassy carbon electrode and screen-printed electrodes [6,7] Wang et al. [8] found that bismuth presents analogous analytical performance when compared to mercury for stripping analysis. This similarity can be explained taking into account the fact that bismuth forms a "fused alloy" with metals [9].

Detection of trace heavy metals needs the removal of dissolved oxygen, stirring and addition of any external metals to improve the sensitivity of electrode surface. During miniaturization of the electroanalytical devices, the above condition needs to be avoided for the analyte detection. We report for the first time the conducting polymer modified electrode (GC/PEDOT/PSS) as a new alternative electrode material for heavy metals detection at micro- molar levels without involving the preparative steps. Further, simultaneous detection of cadmium and lead on a PEDOT/PSS modified glassy carbon electrodes is achieved employing linear sweep anodic stripping voltammetry in acetate buffer solution of $\mathrm{pH}$ 4.5.

The detection of cadmium and lead using conducting polymer modified glassy carbon electrode has not been reported in the literature to the best of our knowledge. The electrodeposited conducting polymer matrices possess advantages such as: 1) thin, uniform and adherent polymer films can be obtained; 2) polymer film can be deposited electrochemically on a small surface area with a high degree of geometrical conformity; and 3) deposition can be effected on selected areas, especially in the 
case of microsensors. Among the numerous polymeric materials developed and studied over the past few decades, polyanilines, polypyrroles and polythiophenes constitute an important class. Among these, polythiophenes have received a significant amount of attention as electrode modifiers in a variety of applications such as organic light-emitting devices, sensors, polymer batteries, electrochromic windows, etc. $[10,11]$. Our group has extensively reported on the use of PEDOT modified electrodes for sensing of biologically important analyte molecules in the recent past $[12,13]$.

\section{Experimental}

\subsection{Materials}

All chemicals were of analytical grade and used without further purification. $1000 \mu \mathrm{g} / \mathrm{ml}$ stock solutions of $\mathrm{Pb}\left(\mathrm{NO}_{3}\right)_{2}$ and $\mathrm{CdCl}_{2}$ were prepared by dissolving the reagents in Milli-Q water (18.2 $\Omega$ ) (Millipore). The monomer, 3,4-ethylenedioxythiophene (EDOT, Aldrich), poly (4-styrenesulphonate) (PSS), tetrabutylammonium perchlorate (TBAPC, Fluka), acetonitrile (E-Merck), were used as received. The acetate buffer solution $(\mathrm{pH} 4.5)$ was prepared by adding $\mathrm{CH}_{3} \mathrm{COONa}$ (E-Merck) to a $\mathrm{CH}_{3} \mathrm{COOH}$ (E-Merck) solution.

For voltammetric studies, a 3-mm diameter glassy carbon disk (BAS Inc.) served as the working electrode with a platinum wire and $\mathrm{Ag} / \mathrm{AgCl}(3 \mathrm{M} \mathrm{NaCl})$ as auxiliary and reference electrodes respectively.

\subsection{Instrumentation}

Voltammetric experiments were carried out using a PalmSens portable electrochemical analyzer (Palmsens $\mathrm{BV}$, The Netherlands) at ambient temperature $\left(25 \pm 1^{\circ} \mathrm{C}\right)$. To record linear sweep voltammetry (LSV), the following input parameters were used: Scan rate: $50 \mathrm{mV} \cdot \mathrm{s}^{-1}$, deposition potential: $-1.1 \mathrm{~V}$, deposition time: $120 \mathrm{~s}$, equilibration time: $5 \mathrm{~s}$.

\subsection{Preparation of PEDOT/PSS - Modified GCE}

The GCE surface was polished first on a fine polishing cloth using 1.0 and $0.06 \mu \mathrm{m}$ alumina powder, and finally sonicated in Milli-Q water for 5 minutes. Before electropolymerization, the polished electrode was pretreated by cycling it between -0.9 to $1.5 \mathrm{~V}$ vs Ag wire at $50 \mathrm{mV}$ $\mathrm{s}^{-1}$ in acetonitrile containing TBAPC for 10 minutes. PEDOT was electrodeposited on the GCE from a solution of $50 \mathrm{mM}$ EDOT $+0.1 \mathrm{M}$ TBAPC in acetonitrile by cycling between -0.9 to $1.5 \mathrm{~V}$ vs Ag wire (pseudo-refer- ence electrode). PEDOT film was allowed to grow on the GC surface over three successive scans, as seen from the increasing anodic and cathodic peak current density values. The electropolymerization of EDOT was highly reproducible and the cyclic voltammograms obtained during the electropolymerization process agreed closely with that reported earlier [14].

To increase the anionic nature of GC/PEDOT film, the electrode was cycled between -0.9 to $1.2 \mathrm{~V}$ vs $\mathrm{Ag} / \mathrm{AgCl}$ reference electrode at $50 \mathrm{mV} \cdot \mathrm{s}^{-1}$ in $1 \%$ PSS solution. This modified electrode is hereafter referred as $\mathrm{GC} /$ PEDOT/PSS

\section{Results and Discussion}

Figure 1 shows the LSASV responses of $20 \mu \mathrm{g} / \mathrm{ml} \mathrm{Cd}^{2+}$ and $\mathrm{Pb}^{2+}$ at bare, PEDOT, PEDOT-PSS modified glassy carbon electrodes. In Figure 1, a relatively small current response is observed at the PEDOT modified GCE (curve b), which shows difficulty for the metal ions to be adsorbed onto the PEDOT surface. This may be reasoned as the cationic nature of the PEDOT materials [15], which does not favor adsorption of cationic metal species on its surface. On the other hand, for the PEDOT-PSS modified GCE electrode, the stripping peak current values for the two metal ions are larger than those obtained from the bare and PEDOT modified GCE electrodes. This can be explained that the PEDOT film doped with PSS exerts negative charges on the surface. These charges can favor accumulation of increasing amounts of the positively charged metal ion on its surface. Hence, the PEDOT film can be used as an excellent supporting material for heavy metal ion sensor. Thus the peak currents of $\mathrm{Cd}^{2+}$ and $\mathrm{Pb}^{2+}$ at the GC/PEDOT/PSS are greatly enhanced, which are attributed to PSS doping of the polymer that exhibits a strong adsorptive power of the heavy metal ions and hence an improved surface sensitivity of the electrode is observed.

Since the preliminary experiments revealed the pertinence of the PEDOT-PSS electrode for trace heavy metal detection by ASV, without involving oxygen removal, alloying additions and stirring, further investigations such as variable experimental conditions affecting the stripping response of the PEDOT-PSS modified GCE are also examined, including the film composition and deposition parameters are carried out.

The anodic stripping response of GC/PEDOT/PSS towards the presence of $\mathrm{Cd}^{2+}$ ion and $\mathrm{Pb}^{2+}$ ion were separately investigated. The respective metal ion standard additions were made to the acetate buffer solution $(\mathrm{pH}$ 4.5) and overlays of the voltammograms along with a standard addition plot of metal ion concentration versus peak current are shown in Figures $\mathbf{2}$ and $\mathbf{3}$ respectively. The calibration plot is linear over the concentration range 


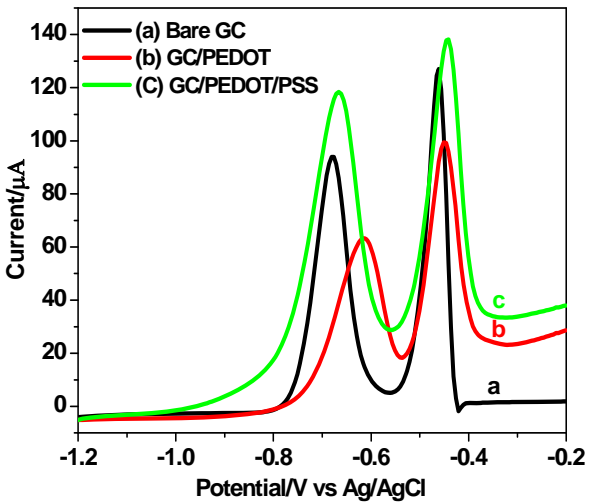

Figure 1. LSASV of cadmium and lead $(20 \mu \mathrm{g} / \mathrm{ml})$ in acetate buffer (pH 4.5) solution. Deposition at $-1.1 \mathrm{~V}$ for $120 \mathrm{~s}$, scan rate $100 \mathrm{mV} \cdot \mathrm{s}^{-1}$. (a) Bare GC (b) GC/PEDOT (c) GC/PEDOT/PSS.

of 4 to $20 \mu \mathrm{g} / \mathrm{ml}$ with a correlation co-efficient of 0.9986 and a calculated limit of detection of $0.96 \mu \mathrm{g} / \mathrm{ml}$ of lead. The $2 \mu \mathrm{g} / \mathrm{ml}$ addition of $\mathrm{Pb}^{2+}$ ion gave a stripping peak from the $4 \mu \mathrm{g} / \mathrm{ml}$ addition and linear calibration plot through to $20 \mu \mathrm{g} / \mathrm{ml}$. The corresponding calibration plot for the additions was linear $\left(\mathrm{R}^{2}=0.9972\right)$ and gave a
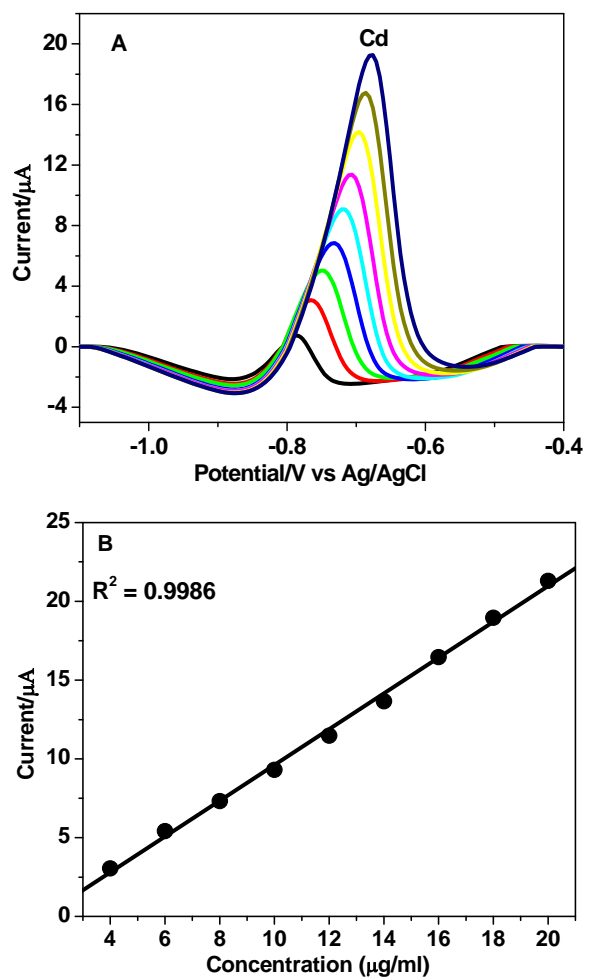

Figure 2. (A) Overlay of LSASVs at a GC/PEDOT/PSS modified electrode in acetate buffer solution (pH 4.5) following the standard additions of $\mathrm{Cd}^{2+}$ over a $4-20 \mu \mathrm{g} / \mathrm{ml}$ concentration range. Deposition at $-1.1 \mathrm{~V}$ for $120 \mathrm{~s}$, scan rate $50 \mathrm{mV} \cdot \mathrm{s}^{-1}$. (B) Calibration plot of peak current versus $\mathrm{Cd}^{2+}$ concentration.
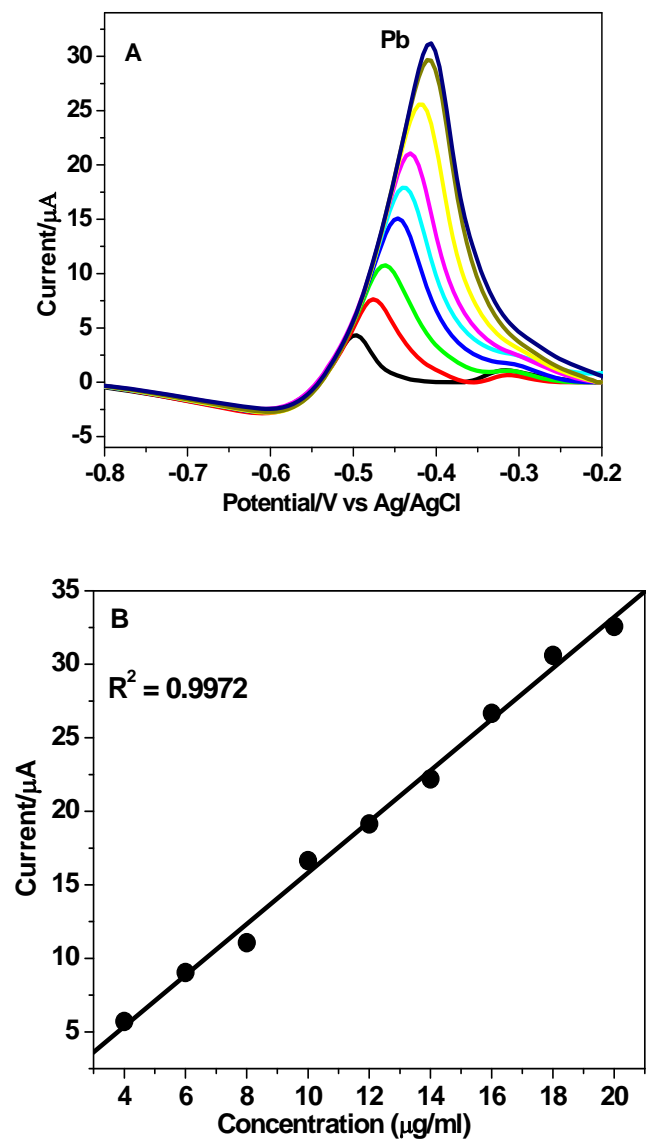

Figure 3. (A) Overlay of LSASVs at a GC/PEDOT/PSS modified electrode in acetate buffer solution (pH 4.5) following the standard additions of $\mathrm{Pb}^{2+}$ over a $4-20 \mu \mathrm{g} / \mathrm{ml}$ concentration range. Deposition at $-1.1 \mathrm{~V}$ for $120 \mathrm{~s}$, scan rate $50 \mathrm{mV} \cdot \mathrm{s}^{-1}$. (B) Calibration plot of peak current versus $\mathrm{Pb}^{2+}$ concentration.

limit of detection of $1.15 \mu \mathrm{g} / \mathrm{ml}$. Following the detection of $\mathrm{Cd}$ and $\mathrm{Pb}$ on the modified electrode individually, simultaneous detection of the two metal ion analytes was attempted. Figure 4 illustrates a series of LSASV for the PEDOT-PSS modified GCE for successive additions of $\mathrm{Cd}^{2+}$ and $\mathrm{Pb}^{2+}$ in $2 \mu \mathrm{g} / \mathrm{ml}$ steps in the concentration range $2-10 \mu \mathrm{g} / \mathrm{ml}$. The voltammogram exhibits well-developed and separated stripping peaks. The characteristic peaks of $\mathrm{Cd}^{2+}$ and $\mathrm{Pb}^{2+}$ were observed at -0.746 and $-0.496 \mathrm{~V}$ respectively, which agree with the individual metal ion stripping characteristics (Figures 2 and 3) with a pre-concentration deposition time of $120 \mathrm{~s}$ (optimized for this condition). The calibration plots for the $\mathrm{Cd}^{2+}$ and $\mathrm{Pb}^{2+}$ are linear in the range of $2-10 \mu \mathrm{g} / \mathrm{ml}$ with regression co-efficient values of 0.9911 and 0.9944 , respectively. The relative standard deviations from 10 measurements for $2 \mu \mathrm{g} / \mathrm{ml} \mathrm{Cd}^{2+}$ and $\mathrm{Pb}^{2+}$ by using the PEDOT-PSS modified electrode are about $3.21 \%$ and $1.96 \%$ respectively. Therefore, the detection limit of $\mathrm{Cd}^{2+}$ and $\mathrm{Pb}^{2+}$ are about $1.47 \mu \mathrm{g} / \mathrm{ml}$ and $1.15 \mu \mathrm{g} / \mathrm{ml}$, respectively. 

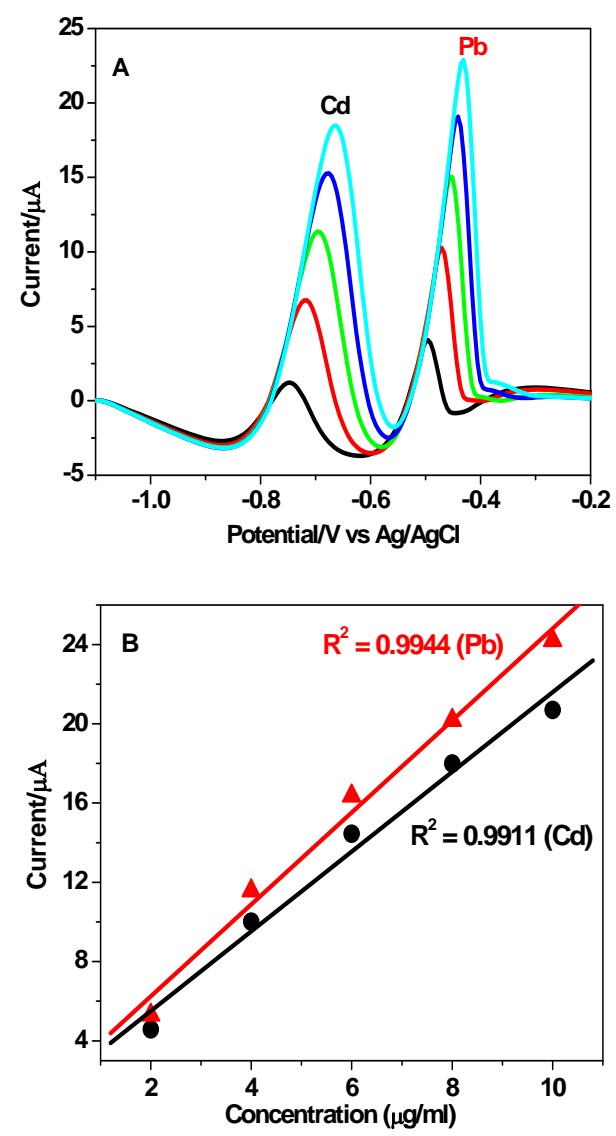

Figure 4. (A) Overlay of LSASVs at a GC/PEDOT/PSS modified electrode in acetate buffer solution (pH 4.5) following the standard additions of $\mathrm{Cd}^{2+}$ and $\mathrm{Pb}^{2+}$ over a 2 - 10 $\mu \mathrm{g} / \mathrm{ml}$ concentration range. Deposition at $-1.1 \mathrm{~V}$ for $120 \mathrm{~s}$, scan rate $50 \mathrm{mV} \cdot \mathrm{s}^{-1}$. (B) Calibration plot of peak current versus $\mathrm{Cd}^{2+}$ and $\mathrm{Pb}^{2+}$ concentration.

\section{Conclusions}

The use of GC/PEDOT/PSS modified glassy carbon electrode for the simultaneous detection of cadmium and lead has been presented. In this preliminary investigation, we have achieved the detection of cadmium and lead simultaneously down to $1.47 \mu \mathrm{g} / \mathrm{ml}$ and $1.15 \mu \mathrm{g} / \mathrm{ml}$ respectively, using conducting polymer modified glassy carbon electrode in acetate buffer $(\mathrm{pH} 4.5)$ without the removal of dissolved oxygen, stirring and any external metals like $\mathrm{Hg}, \mathrm{Bi}, \mathrm{Sb}$, etc. The merits of polymer-modified electrode are: enhanced electroanalytical sensitivity, stability and increased mass transport that facilitate estimation of heavy metals at trace levels. Thus, the GC/PEDOT/PSS modified electrode can be a suitable candidate for the detection of heavy metals. Further optimization using this polymer modified electrode to detect nanomolar/sub-nanomolar level of heavy metals and also the simultaneously detection of other heavy metals without involving the pre-concentration step is in progress.

\section{Acknowledgments}

The authors thank the Department of Biotechnology, New Delhi for financial assistance [BT/PR-10459/BCE/ 08/651/2008].

\section{References}

[1] M. Heitzmann, L. Basaez, F. Brovelli, C. Bucher, D. Limosin, E. Pereira, B. L. Rivas, G. Yal, E. Saint-Aman and J. C. Moutet, "Voltammetric Sensing of Trace Metals at a Poly (Pyrrole - Malonic Acid ) Film Modified Electrode," Electroanalysis, Vol. 17, No. 21, 2005, pp. 19701976. doi:10.1002/elan.200503325

[2] J. Wang, "Analytical Electrochemistry," Wiley-VCH, New York, 1994.

[3] J. C. Ball and R. G. Compton, "Anodic Stripping Voltammetry at Hydrodynamic Mercury Electrodes. Square Wave Voltammetry: Numerical Theory for Electrochemically Reversible Systems," Journal of Physical Chemistry B, Vol. 102, No. 20, 1998, pp. 3967-3973. doi:10.1021/jp980749k

[4] E. Fisher and C. M. G. Van den Berg, "Anodic Stripping Voltammetry of Lead and Cadmium Using a Mercury Film Electrode and Thiocyanate," Analytica Chimica Acta, Vol. 385, No. 1-3, 1999, pp. 273-280. doi:10.1016/S0003-2670(98)00582-0

[5] V. P. Gladyshev, S. V. Kovaleva and N. A. Khramtsova, "Determination of Ammonium by Stripping Voltammetry," Journal of Analytical Chemistry, Vol. 56, No. 5, 2001, pp. 443-448. doi:10.1023/A:1016627003444

[6] J. Zen and Y. Ting, "Square-Wave Voltammetric Stripping Analysis of Lead (II) at a Nafion/Copper-Mercury Film Electrode," Analytica Chimica Acta, Vol. 332, No. 1, 1996, pp. 59-65. doi:10.1016/0003-2670(96)00215-2

[7] J. Wang and B. Tian, "Screen-Printed Stripping Voltammetric/Potentiometric Electrodes for Decentralized Testing of Trace Lead," Analytica Chimica Acta, Vol. 64, No. 15, 1992, pp. 1706-1709.

[8] J. Wang, J. Lu, S. B. Hocevar and P. A. M. Farias, "Bismuth - Coated Carbon Electrodes for Anodic Stripping Voltammetry," Analytical Chemistry, Vol. 72, No. 14, 2000, pp. 3218-3222. doi:10.1021/ac000108x

[9] K. E. Toghil, G. G. Wildgoose, A. Moshar, C. Mulcahy and R. G. Compton, "The Fabrication and Characterization of a Bismuth Nanoparticle Modified Boron Doped Diamond Electrode and Its Application to the Simultaneous Determination of Cadmium (II) and Lead (II)," Electroanalysis, Vol. 20, No. 16, 2008, pp. 1731-1737. doi:10.1002/elan.200804277

[10] K. Krishnamoorthy, R. S. Gokhale, A. Q. Contractor and A. Kumar, "Novel Label - Free DNA Sensors Based on Poly (3,4-ethylenedioxythiophene)," Chemical Communications, Vol. 10, No. 7, 2004, pp. 820-821. doi:10.1039/b316794a

[11] H. Yamato, M. Ohwa and W. Wernet, "Stability of Polypyrrole and Poly (3,4-Ethylenedioxythiophene) for Bio- 
sensor Application," Journal of Electroanalytical Chemistry, Vol. 397, No. 1-2, 1995, pp. 163-170.

doi:10.1016/0022-0728(95)04156-8

[12] S. Senthilkumar, J. Mathiyarasu and K. L. N. Phani, "ExPloration of Synergism between a Polymer Matrix and Gold Nanoparticles for Selective Determination of Dopamine," Journal of Electroanalytical Chemistry, Vol. 578, No. 1, 2005, pp. 95-103. doi:10.1016/j.jelechem.2004.12.023

[13] S. Senthilkumar, J. Mathiyarasu, K. L. N. Phani and Y. Yegnaraman, "Simultaneous Determination of Dopamine and Ascorbic Acid on Poly (3,4-Ethylenedioxythiophene) Modified Glassy Carbon Electrode," Journal of Solid State Electrochemistry, Vol. 10, No. 11, 2006, pp. 905-
913. doi:10.1007/s10008-005-0041-7

[14] V. S. Vasantha and K. L. N. Phani, "Effect of Hydroxypropyl- $\beta$-Cyclodextrin on the Electrochemical Oxidation and Polymerization of 3,4-Ethylenedioxythiophene," Journal of Electroanalytical Chemistry, Vol. 520, No. 1, 2002, pp. 79-88.

doi:10.1016/S0022-0728(01)00748-3

[15] M. M. de Kok, M. Buechel1, S. I. E. Vulto, P. van de Weijer, E. A. Meulenkamp, S. H. P. M. de Winter, A. J. G. Mank, H. J. M. Vorstenbosch, C. H. L. Weijtens and V. van Elsbergen, "Modification of PEDOT: PSS as Hole Injection Layer in Polymer LEDs," Physica Status Solidi (A), Vol. 201, No. 6, 2004, pp. 1342-1359. doi:10.1002/pssa.200404338 